\title{
Efficacy and Side Effects of Fractional Carbon Dioxide Laser for Acne Scars, Keloids, and Striae Albae in the Dermatovenereology Clinic of Tertiary Hospital: A Retrospective Study
}

\author{
Riezky Januar Pramitha ${ }^{1}$, Iskandar Zulkarnain ${ }^{1}$, Evy Ervianti ${ }^{1}$, Rahmadewi ${ }^{1}$, Afif Nurul \\ Hidayati $^{1}$, Budiono ${ }^{2}$, Diah Mira Indramaya ${ }^{1}$, Trisniartami Setyaningrum ${ }^{1}$, Irmadita \\ Citrashanty $^{1}$, Maylita Sari', Menul Ayu Umborowati ${ }^{1}$, Bagus Haryo Kusumaputra ${ }^{1}$, \\ Muhammad Yulianto Listiawan ${ }^{1}$ \\ ${ }^{I}$ Department of Dermatology and Venereology, Faculty of Medicine, Universitas Airlangga, Dr. \\ Soetomo General Academic Teaching Hospital, Surabaya, Indonesia \\ ${ }^{2}$ Department of Public Health Sciences, Faculty of Medicine, Universitas Airlangga, Surabaya, \\ Indonesia
}

\begin{abstract}
Background: Fractional Carbon Dioxide $\left(\mathrm{CO}_{2}\right)$ LASER has better efficacy compared to conventional LASER in treating scar tissue such as acne scars, keloids, and striae albae. However, a population with darker skin has a higher risk of side effects, especially in post-inflammatory hyperpigmentation. Purpose: To evaluate the efficacy and side effects of fractional $\mathrm{CO}_{2}$ LASER in new patients with acne scars, keloids, and striae albae in the Dermatovenereology outpatient clinic. Methods: Retrospective analysis was done on 42 medical records of patients who met the inclusion criterion, which was those who have undergone fractional $\mathrm{CO}_{2}$ LASER treatments. The efficacy and side effects of the therapy were identified and analyzed using the Statistical Package for Social Sciences (SPSS) version 17 program. Result: A total of $42.9 \%$ of patients underwent fractional $\mathrm{CO}_{2}$ LASER treatments for acne scars, while $31 \%$ and $26.1 \%$ of patients received treatments for keloids and striae albae, respectively. There was a statistically significant decrease in the degree of acne scar (2.72 \pm 0.83$)$, keloid height $(2.2 \pm$ $0.405)$, and striae width $(0.39 \pm 0.02)$. The statistically significant side effects were hyperpigmentation $(59.5 \%)$, crustae (26.2\%), erythema $\geq$ for 4 days $(19 \%)$, and new acne $(19 \%)$. Conclusion: Fractional $\mathrm{CO}_{2}$ LASER was effective for treating scar tissue (acne scars, keloids, and striae albae) with a higher incidence of side effects in population with darker skin and post-inflammatory hyperpigmentation.
\end{abstract}

Keywords: Fractional $\mathrm{CO}_{2}$ LASER, side effects, efficacy, scar.

Correspondence: Muhammad Yulianto Listiawan, Department of Dermatology and Venerology, Faculty of Medicine, Universitas Airlangga, Dr. Soetomo General Academic Hospital, Surabaya, J1. Mayjen Prof. Dr. Moestopo No. 6-8 Surabaya 60131, Indonesia. Phone: (031) 5501609, e-mail: yuliantowawan@yahoo.com

\section{BACKGROUND}

Light Amplification of Stimulated Emission of Radiation (LASER) is a device that produces electromagnetic rays with monochromatic, coherent, and collimated characteristics. The emergence of the Fractional Photothermolysis (FP) theory, which was developed to overcome the side effects of conventional LASER, became a milestone in the development of LASER in the field of dermatology. FP is divided into ablative (aFP) and non-ablative Fractional Photothermolysis (nFP). One of the rapidly developed and frequently used aFP modalities is the fractional $\mathrm{CO}_{2}$ LASER. Fractional $\mathrm{CO}_{2}$ LASER is not only effective for skin rejuvenation but also for treating scar tissue, such as acne scars, keloids, and striae albae (SA). ${ }^{1-4}$

Research conducted by Chapas and colleagues on acne scar in patients with skin types I to III stated that there was an increase of $25 \%-50 \%$ in texture, atrophy, and improvement of the acne scar after receiving treatment with fractional $\mathrm{CO}_{2}$ LASER. ${ }^{6,7}$ A study by Scrimali and colleagues in 2010 stated that there was a decrease in the size of keloid height by $20-25 \%$ in 6 months post-therapy, while a study on SA by Naeni in 2014 stated that there was a decrease in SA measurements with the average of $0.62 \pm 0.53$ in length and $0.41 \pm 0.43$ in width. Although it has better efficacy compared to conventional LASER, fractional $\mathrm{CO}_{2}$ LASER has a higher risk of side effects such as hyperpigmentation, erythema, edema, crustae, squama, or bacterial or viral infections, especially in darker skin phototypes such as the Asian population. ${ }^{8-10}$ This is the authors' background to discuss the efficacy and side effects of using fractional $\mathrm{CO}_{2}$ LASER in new patients with acne scars, keloids, and SA. 
This retrospective analytical study was made to determine the efficacy and side effects of fractional $\mathrm{CO}_{2}$ LASER in new patients with acne scars, keloids, and SA in the Dermatovenereology Clinic of Dr. Soetomo General Academic Hospital Surabaya from January 2017 to December 2018. This retrospective study is expected to contribute to the more appropriate use of the fractional $\mathrm{CO}_{2}$ LASER modality.

\section{METHODS}

This was a retrospective study with an analytic design. The population of this study was medical records of new patients with acne scars, keloids, and SA at the Dermatovenereology Outpatient Clinic of Dr. Soetomo General Academic Hospital Surabaya from January 2017 to December 2018. The data was obtained secondarily from medical records.

The inclusion criteria were any medical records of new patients with acne scars, keloids, and SA who underwent fractional $\mathrm{CO}_{2}$ LASER at the Dermatovenereology Outpatient Clinic of Dr. Soetomo General Academic Hospital Surabaya from January 2017 to December 2018. Basic demographic data, diagnosis, duration of complaint, skin phototype, clinical changes, and side effects were recorded. Those data were then inputed into a data collection sheet to be analyzed using the Statistical Package for Social Sciences (SPSS) 17 version.

\section{RESULT}

The study population size was 65 new, and 42 patients' medical records met the sample acceptance criteria. The new patients who underwent fractional $\mathrm{CO}_{2}$ LASER treatment were mostly patients with acne scars $(42.9 \%)$, followed by keloids $(31 \%)$, and SA (26.1\%). Patients' demographic data were assessed based on sex, age and skin type according to Fitzpatrick's classification, occupation, diagnosis, and duration of illness.

Table 1 shows the demographic distribution of new patients undergoing fractional $\mathrm{CO}_{2}$ LASER treatment in the Dermatovenereology Outpatient Clinic of Dr. Soetomo General Academic Hospital Surabaya from January 2017 to December 2018. More female patients underwent fractional $\mathrm{CO}_{2}$ LASER than the male. In a year, there were 42 new patients, consisting of 26 female patients $(61.90 \%)$ and 16 male patients (38.09\%). All study participants were above 18 years old. The youngest was 20 years old, and the oldest was 54 years old. The mean age of the study was $29.57 \pm$ 8.28 years. The most common Fitzpatrick skin type of the study was type IV, with as many as 21 people (50\%), followed type V (38.10\%), and type III $(11.90 \%)$. We found no patient with skin type I and type II. The patient's occupation was grouped into indoor and outdoor occupations. $92.86 \%$ of the participants worked indoors, and the remaining $7.14 \%$ worked outdoor.

In this study, we found that male patients were more likely to be diagnosed with acne scars, while female patients were more likely to be diagnosed with SA and keloids. Among all acne scars patients, $61.11 \%$ were males and only $38.89 \%$ were females. Patients diagnosed with SA who underwent fractional $\mathrm{CO}_{2}$ LASER treatment were all females. In patients with keloids, $61.53 \%$ were females, and $38.46 \%$ were males. Those three groups were then tested using the Pearson Chi-Square test, and the results showed a significant difference with $p$-value $=0.004$. The mean age of the three diagnosis groups was also found to be significantly different with $\mathrm{p}=0.001$.

The clinical efficacy in this study was based on improvements in acne scars, changes in SA length and width, and changes in keloid height. We evaluate patients with acne scars after three treatment sessions, and we evaluate keloid and SA patients after one treatment session. Clinically, we classified them according to the qualitative grading scale of acne scars proposed by Goodman and Baron criteria. Improvements in the degree of acne scar before and after fractional $\mathrm{CO}_{2}$ LASER treatment can be seen in Table 3. In the initial examination, no patient fell under the grade I acne scars, $44.44 \%$ of the patients fell under the grade IV acne scars, $27.78 \%$ of the patients fell under the grade II, and $27.78 \%$ of the patients fell under the grade III. After the fractional $\mathrm{CO}_{2}$ LASER treatment, $50 \%$ of the patients fell under the grade II acne scars, and $27.78 \%$ fell under the grade III acne scars.

All study samples were evaluated using secondary data regarding the side effects that arose after fractional $\mathrm{CO}_{2}$ LASER treatment. $69 \%$ of the patients reported side effects, and no side effects were reported in $31 \%$ of them. The analysis test results were statistically significant, as shown in Table 4.

Table 5 shows a statistically significant relationship between fluency and the diagnosis and the occurrence of side effects. However, there is no significant difference between skin type, sex, and duration of illness, and the occurrence of side effects. A higher mean fluence was found in patients who experienced side effects (11.4).

In Table 6, almost all patients with acne scars and SA who received fractional $\mathrm{CO}_{2}$ LASER treatment reported side effects. Meanwhile, only one patient with keloid $(7.7 \%)$ reported side effects. The statistical test resulted in a significant difference with $<0.001 \mathrm{p}$-value. 
Table 1. Distribution of new patients with acne scars, keloids, and SA who underwent fractional $\mathrm{CO}_{2} \mathrm{LASER}$ treatment in the Dermatovenereology Outpatient Clinic of Dr. Soetomo General Academic Hospital Surabaya from January 2017 to December 2018

\begin{tabular}{|c|c|}
\hline Variables & Total $\mathrm{n}(\%)$ \\
\hline \multicolumn{2}{|l|}{ Sex } \\
\hline Male & $16(38.09)$ \\
\hline Female & $26(61.90)$ \\
\hline Mean Age (years \pm SD) & $29.57 \pm 8.28$ \\
\hline \multicolumn{2}{|l|}{ Fitzpatrick Skin Phototype } \\
\hline Type I & $0(0)$ \\
\hline Type II & $0(0)$ \\
\hline Type III & $5(11.90)$ \\
\hline Type IV & $21(50)$ \\
\hline Type V & $16(38.10)$ \\
\hline Type VI & $0(0)$ \\
\hline \multicolumn{2}{|l|}{ Occupation } \\
\hline Indoor & $39(92.86)$ \\
\hline Outdoor & $3(7.14)$ \\
\hline \multicolumn{2}{|l|}{ Diagnosis } \\
\hline Acne Scars & $18(42.9)$ \\
\hline Keloids & $13(31)$ \\
\hline Striae albae & $11(26.1)$ \\
\hline Duration of Illness (years \pm SD) & $8.26 \pm 5.79$ \\
\hline
\end{tabular}

Note: SD = Standard Deviation

Table 2. Comparison of patient demographics with clinical diagnosis

\begin{tabular}{|c|c|c|c|c|c|}
\hline Variables & $\begin{array}{c}\text { Acne Scars } \\
(\mathrm{n}=18)\end{array}$ & $\begin{array}{l}\text { Striae Albae } \\
\quad(\mathrm{n}=11)\end{array}$ & $\begin{array}{l}\text { Keloids } \\
(\mathrm{n}=13)\end{array}$ & $\begin{array}{c}\text { Total } \\
(\mathrm{n}=42)\end{array}$ & $\mathrm{p}$ \\
\hline Sex & & & & & $0.004 *$ \\
\hline Male & $11(61.11)$ & $0(0)$ & $5(38.46)$ & $16(38.09)$ & \\
\hline Female & $7(38.89)$ & $11(100)$ & $8(61.53)$ & $26(61.90)$ & \\
\hline Age (in years) & $26.5(22-35)$ & $37(26-51)$ & $22(20-54)$ & $28(20-54)$ & $0.001 *$ \\
\hline Fitzpatrick Skin & & & & & 0.091 \\
\hline \multicolumn{6}{|l|}{ Phototype } \\
\hline Type I & $0(0)$ & $0(0)$ & $0(0)$ & $0(0)$ & \\
\hline Type II & $0(0)$ & $0(0)$ & $0(0)$ & $0(0)$ & \\
\hline Type III & $3(16.67)$ & $0(0)$ & $2(15.38)$ & $5(11.90)$ & \\
\hline Type IV & $10(55.56)$ & $4(36.36)$ & $7(53.84)$ & $21(50)$ & \\
\hline Type V & $5(27.78)$ & $7(63.63)$ & $4(30.77)$ & $16(38.10)$ & \\
\hline Occupation & & & & & $0.027 *$ \\
\hline Indoor & $18(100)$ & $11(100)$ & $10(76.92)$ & $39(92.86)$ & \\
\hline Outdoor & $0(0)$ & $0(0)$ & $3(23.08)$ & $3(7.14)$ & \\
\hline $\begin{array}{l}\text { Duration of Illness } \\
\text { (years) }\end{array}$ & $81 \pm 5.69$ & $12.27 \pm 5.69$ & $5.08 \pm 4.03$ & $8.26 \pm 5.79$ & $0.007 *$ \\
\hline
\end{tabular}


Table 3. The comparison of clinical evaluations before and after fractional $\mathrm{CO}_{2} \mathrm{LASER}$ treatment

\begin{tabular}{|c|c|c|c|}
\hline Variables & Before LASER treatment & After LASER treatment & $\mathrm{p}$ \\
\hline \multicolumn{4}{|l|}{ Acne Scars } \\
\hline Degree of acne scars & & & $0.005^{*}$ \\
\hline I & 0 & 0 & \\
\hline II & $5(27.78 \%)$ & $9(50 \%)$ & \\
\hline III & $5(27.78 \%)$ & $5(27.78 \%)$ & \\
\hline IV & $8(44.44 \%)$ & $4(22.22 \%)$ & \\
\hline Mean \pm SD (category) & $3.17 \pm 0.86$ & $2.72 \pm 0.83$ & \\
\hline \multicolumn{4}{|l|}{ Striae albae } \\
\hline Length (median) & 38.1 & 36.0 & 0.075 \\
\hline Width (median) & 3.6 & 3.2 & $0.001 *$ \\
\hline \multicolumn{4}{|l|}{ Keloids } \\
\hline Height (mm) & $3.85 \pm 1.53$ & $1.65 \pm 1.125$ & $0.000 *$ \\
\hline
\end{tabular}

Note: $\mathrm{SD}=$ Standard Deviation, *Statistically significant

Table 4. The incidence of side effects

\begin{tabular}{lcc}
\hline \multicolumn{1}{c}{ Variables } & Total & $\mathrm{p}$ \\
\hline Side Effects & & $0.000^{*}$ \\
Present, $\mathrm{n}(\%)$ & $29(69 \%)$ & \\
Absent, n (\%) & $13(31 \%)$ & \\
Total & $42(100 \%)$ & \\
\hline
\end{tabular}

Note: *Statistically significant

Table 5. The comparison of side effects incidence after the fractional $\mathrm{CO}_{2}$ LASER treatment

\begin{tabular}{lccc}
\hline \multicolumn{1}{c}{ Variables } & $\begin{array}{c}\text { Side Effects Present } \\
(\mathrm{n}=29)\end{array}$ & $\begin{array}{c}\text { Side Effects Absent } \\
(\mathrm{n}=13)\end{array}$ & $\mathrm{p}$ \\
\hline SPT & 4.31 & 4.15 & 0.480 \\
Mean fluence $\left(\mathrm{J} / \mathrm{cm}^{2}\right)$ & 11.4 & 4.5 & $0.000^{*}$ \\
Male percentage & $11(37.93)$ & $5(38.46)$ & 0.618 \\
Female percentage & $18(62.06)$ & $8(61.54)$ & 0.618 \\
Acne scar percentage & $17(94.4)$ & $1(5.6)$ & $0.000^{*}$ \\
Striae albae percentage & $11(100)$ & $0(0)$ & $0.000^{*}$ \\
Keloid percentage & $1(7.7)$ & $12(92.3)$ & $0.000^{*}$ \\
Mean duration of illness & 9.31 & 5.92 & 0.093 \\
\hline
\end{tabular}

Note: *Statistically significant

SPT: Fitzpatrick Skin Type

Table 6. Comparison of side effects after fractional $\mathrm{CO}_{2}$ LASER treatment

\begin{tabular}{|c|c|c|c|c|c|}
\hline Variables & $\begin{array}{c}\text { Acne Scars } \\
(\mathrm{n}=18)\end{array}$ & $\begin{array}{l}\text { Striae albae } \\
\quad(\mathrm{n}=11)\end{array}$ & $\begin{array}{l}\text { Keloids } \\
(\mathrm{n}=13)\end{array}$ & $\begin{array}{c}\text { Total } \\
(\mathrm{n}=42)\end{array}$ & $\mathrm{p}$ \\
\hline Side effects & & & & & $0.000^{*}$ \\
\hline Present, n (\%) & $17(94.4)$ & $11(100)$ & $1(7.7)$ & $29(69)$ & \\
\hline Absent, n (\%) & $1(5.6)$ & $0(0)$ & $12(92.3)$ & $13(31)$ & \\
\hline \multicolumn{6}{|l|}{ Types of side effects } \\
\hline Hyperpigmentation & $1(5.6)$ & $11(100)$ & $13(100)$ & $25(59.5)$ & $0.000^{*}$ \\
\hline Crustae & $11(61.1)$ & $0(0)$ & $0(0)$ & $11(26.2)$ & $0.000 *$ \\
\hline Erythema $\geq 4$ days & $8(44.4)$ & $0(0)$ & $0(0)$ & $8(19)$ & $0.001 *$ \\
\hline New Acne & $8(44.4)$ & $0(0)$ & $0(0)$ & $8(19)$ & $0.001 *$ \\
\hline Edema $\geq 2$ days & $4(22.2)$ & $0(0)$ & $0(0)$ & $4(9.5)$ & 0.052 \\
\hline Hypopigmentation & $0(0)$ & $0(0)$ & $1(7.7)$ & $1(2.4)$ & 0.319 \\
\hline
\end{tabular}

Note: *Statistically significant 


\section{DISCUSSION}

There were 42 medical records of new patients who had fractional $\mathrm{CO}_{2}$ LASER treatment at the Dermatovenereology Outpatient Clinic of Dr. Soetomo General Academic Hospital Surabaya from January 2017 to December 2018. Among all patients, $61.90 \%$ were females and $38.09 \%$ of them were males. The results were in line with a retrospective study conducted at the Washington Institute of Dermatologic LASER Surgery in 2011 by Emmy and colleagues. In that study, 384 female patients underwent fractional $\mathrm{CO}_{2}$ LASER treatment. That number was far higher than the number of male patients or about $91 \%$ of the total patients. It was hypothesized that female patients generally tend to pay more attention to cosmetic problems than males. ${ }^{11}$

The mean age of this study was $29.57 \pm 8.28$ years. The youngest was 20 years old, and the oldest was 54 years old. The participants presented with skin types between type III-V. We found that type IV was the most common Fitzpatrick skin phototypes, as reported in 21 people $(50 \%)$, followed by type V $(38.10 \%)$, and type III $(11.90 \%)$. This was in accordance with research conducted by Lee SM and colleagues in 2014. They reported that there was no age limit or contraindication for fractional $\mathrm{CO}_{2}$ LASER treatment, yet patients should have understood and cooperated during the procedure. ${ }^{12}$

Most of the study participants worked indoors than outdoor, $92.86 \%$ and $7.14 \%$, respectively. It was assumed that indoor workers tended to have more time to check up on their condition, and they tended to have direct interaction more frequently. Therefore, they cared more about their appearance. Fractional $\mathrm{CO}_{2}$ LASER has been used as a therapeutic modality in various indications, namely acne scars, SA, and keloids. The goal of this therapy is to restore the aesthetic skin as naturally as possible.

This retrospective study found that the new patients who underwent fractional $\mathrm{CO}_{2}$ LASER treatment were mostly those diagnosed with acne scars, which was $42.9 \%$. In table 2 , the mean age of 26.5 years $(22-35$ years old). $61.11 \%$ of the patients diagnosed with acne scars were male, and $38.89 \%$ of them were females. These results were in accordance with a retrospective study conducted in Singapore in 2017 by Harumi and colleagues. They reported that out of a total of 107 acne scars patients, $59 \%$ of them were males, while $41 \%$ were females. ${ }^{8}$ The findings were also following the research conducted by Qian and colleagues in 2012 and Hsiao and colleagues in 2013. Qian and colleagues' retrospective study showed that from a total of 31 patients with acne scars who underwent fractional $\mathrm{CO}_{2}$ LASER, 20 of them were males. Meanwhile, Hsiao et al., in Taiwan reported that there were 19 male patients from a total of 25 acne scars patients who underwent fractional $\mathrm{CO}_{2}$ LASER treatment. ${ }^{13}$ This might relate to the theory of acne vulgaris. Epidemiologically, the prevalence of acne vulgaris peaks in mid to late adolescence, with $85 \%$ occurring in adolescence. The general incidence of acne vulgaris in males was 70.4/1000 and 65.8/1000 in females. The incidence of acne scars was also found in men, which was around $2 / 1000$ and $1.3 / 1000 .^{13-15}$

The pathogenesis of acne vulgaris is said to be related to sebum production as increased by androgen hormone and decreased by estrogen hormone. Some theories suggest that the occurrence of acne vulgaris is due to the hyperresponsive reaction of sebocytes and keratinocytes to androgens, triggering follicle clogging and stimulating an inflammatory response to $P$. acnes around the follicle, especially on the skin with an increase in $\mathrm{pH}$. This theory is in line with the results obtained from this study. We found more incidences in males, and they generally have higher levels of androgen hormone. ${ }^{14,15}$

All SA patients who underwent fractional $\mathrm{CO}_{2}$ LASER treatment in this study were females. In this study, patients that were diagnosed with striae were in the phase of whitish lesions, also known as SA. The mean age of the patients was 37 years with the age range between $26-51$ years. SA is one of the phases in striae distensae marked by a purplish to whitish change in color. This study was in line with the research conducted by Gonzales \& Navalta in 2012 which stated that SA can be found in both sexes. However, it is more common in females, especially pregnant women and usually appears in mid-pregnancy. Risk factors in SA include obesity, a family history of striae, and the use of drugs such as corticosteroids. SA is scar tissue, the epidermal layer is usually thinner and flattened, and the histopathological image will show the loss of the normal rete ridges pattern. ${ }^{16}$ Moreover, the dermis experiences thinning, indicating the occurrence of dermal atrophy that causes cosmetic problems. It can lead to psychological problems as well. Crocco et al. stated that complaints of SA could occur at any age with the most incidence in 23-49 years old. In this study, the duration of the SA complaints ranged from $12.27 \pm 5.69$ years. This might be related to the type of striae distensae, which was striae albae. It is a development of striae rubrae which indicates that the formation of SA takes more time. ${ }^{17}$ Research conducted by Himdani and colleagues in 2014 found that the average age range of women experiencing striae distensae was 23-27 years old. The mean age of the patients in this study was 37 years old, from which 
age the patients experienced SA as a continuation of striae rubrae, the initial phase of striae distensae. ${ }^{18}$

In this study, there were more females diagnosed with keloid $(61.53 \%)$ than males $(38.46 \%)$. This was in accordance with research conducted by Tsal and Ogawa in 2019. They reported that women, especially pregnant women, have a higher risk of scar formation. This is due to the vasodilating effect of estrogen which can promote the movement of immune factors and cells into a wound or scar tissue, exacerbating local inflammation. Local inflammation can happen by itself or as influenced by systemic factors inducing persistent inflammation in subsequent wounds and scars. This inflammation can trigger prolonged fibroblast activity and inhibit the maturation of scar tissue. Keloid itself is also a scar tissue that grows beyond the limit of the initial wound. Histopathologically, keloids show excess collagen bundles. This excess collagen is caused by an imbalance between the formation and degradation of the extracellular matrix. Epidemiologically, keloids affect $4.5 \%$ to $16 \%$ of the general population. Keloids can occur in all ethnicities but are more common in African, Asian, and to a lesser extent in Hispanic and Mediterranean people. The mean age of patients in this study was 22 years ranged between 20-54 years old., 3,19

According to Chike-Obi and colleagues, keloids can occur at any age. However, the highest incidence is between 11-30 years old. The predilection age is thought to be influenced by higher hormone levels compared to normal skin tissue fibroblasts. The patients' duration of illness in this study varied between $5.08 \pm 4.03$ years. Older keloids tend to be more difficult to treat because of a more stable collagen phenotype. Unstable type 3 collagen is produced at the beginning of keloid formation and will turn into type 1 collagen which is more stable over time. Collagen type 1 is no longer degraded by matrix metalloproteinase (MMP) at the end of the remodeling phase. Excessive angiogenesis in older keloids also supports the resistance of fibroblast cells, making them more difficult to treat. ${ }^{3,4,9}$

Most patients with acne scars, SA, and keloid patients had type IV and V skin phototypes. The statistical analysis result showed no difference between the three groups $(\mathrm{p}=0.091)$. A similar result was discovered in a study conducted by Abdul Majeed and colleagues in 2011 in Saudi Arabia. They reported that the majority of a total of 82 acne scar patients who received fractional $\mathrm{CO}_{2}$ LASER treatment had type IV skin. That was in contrast to a study conducted by Emmy and colleagues in 2011 in Washington, United States. They found that an average of 422 patients who underwent a fractional $\mathrm{CO}_{2}$ LASER procedure had type II skin. ${ }^{18,20}$

Keloids are more common in darker skin types. Hochman and colleagues in 2012 reported that out of a total of 146 keloid patients, $47 \%$ of patients had type III skin, while type I and type II skins respectively were only $0.7 \%$ and $8.9 \%$ with a significant difference $(\mathrm{p}=$ 0.025). It indicated that the higher the skin type, the higher the tendency to form keloids. Epidemiologically, keloids are more common in African, Spanish (Hispanic/Latino), or East Asian descents where it is related to levels of melanocytes, melanin, or alpha-melanocyte-stimulating hormone ( $\alpha$ MSH). Melanocytes will produce and release melanogenic neuropeptides $\alpha-\mathrm{MSH}$ and corticotropin (adrenocorticotropic hormone, ACTH), a catecholamine receptor for L-dihydroxyphenylalanine (L-DOPA) and serotonin. If endogenous stressors are present, such as inflammation or external stimuli such as UV rays, melanocytes will act as a "sensor" in the epidermis and act as a "cutaneous nervous system" so that it can control inflammation, immunity, regulation of cutaneous structures, thermoregulation, modulation of homeostasis, and wound healing. . $^{3,419}$

The clinical efficacy in this study was based on changes in the degree of the acne scarring, length, and width in SA, and keloid height. Patients with acne scars were evaluated after three sessions of treatment, while keloid and SA patients were evaluated after only one treatment session. In 2013, Magnani reported that one session of fractional $\mathrm{CO}_{2}$ LASER treatment was enough to provide significantly improved clinical outcomes in the scar. However, carrying out more treatment sessions could provide greater efficacy. ${ }^{13}$

The clinical efficacy in acne scars was evaluated based on changes in the degree of acne scar before and after fractional $\mathrm{CO}_{2}$ LASER treatment, as seen in Table 3. In the initial examination, before the procedure, it was found that most patients were in grade IV acne scar (44.44\%), followed by grade II and III at $27.78 \%$ each. No patient fell under the grade I acne scar. After fractional $\mathrm{CO}_{2}$ LASER treatment, $50 \%$ of the patients had grade II acne scars and $27.78 \%$ of them had grade III acne scars. The clinical improvement was marked by a decrease in the mean degree of acne scars, from $3.17 \pm 0.86$ to $2.72 \pm 0.83$. The results of the data analysis showed a statistically significant difference in the degree of acne scar before and after fractional $\mathrm{CO}_{2}$ LASER with a p-value of 0.005 . A study conducted by Harumi Ochi and colleagues in 2017 also showed that clinical improvement after fractional $\mathrm{CO}_{2}$ LASER treatment resulted in an improvement in the degree of acne scarring by $25 \%-50 \% 1$-month post-treatment. ${ }^{8}$ 
The clinical evaluation of keloids was measured per keloid height using a ruler in millimeters. The results showed a decrease in the mean of keloid height before $(3.85 \pm 1.53 \mathrm{~mm})$ and 6 months after the Fractional $\mathrm{CO}_{2}$ LASER treatment $(1.65 \pm 1.125 \mathrm{~mm})$. The statistical test results showed a significant difference with a value of $\mathrm{p}=0.000$, as shown in Table 3 .

In this study, the length and width of keloids were not analyzed as a parameter of treatment improvement because those were relatively unchanged with therapy. On the other hand, changes in keloid height tend to be more visible. Scrimali and colleagues in 2010 also used keloid height as a parameter for clinical improvement of keloids. In that study, the efficacy of fractional $\mathrm{CO}_{2}$ LASER treatment was measured using a computer application. The study subjects were females aged 2055 years old with skin types of II-IV. All subjects then received fractional $\mathrm{CO}_{2}$ LASER treatment monthly with modified parameters. It resulted in a decrease in keloid height by $20 \%-25 \%$ after 6 months post-therapy in all twelve keloids that had been given treatment. ${ }^{20}$

The clinical changes of SA lesions were represented by measurements of its length and width. These measurements were carried out by taking photographs of the SA lesion before and after the treatment, where the length and width were measured by drawing a straight line along the lesion using image meter software version 2.15.0. The software sized the SA digitally for accurate measurements. The clinical evaluation of SA was carried out based on changes in the length and width of the lesion before and after fractional $\mathrm{CO}_{2}$ LASER treatment. From the measurement, there was a decrease in the mean length before the treatment and after the treatment, which was $3 \pm 0.85$. However, it is not statistically significant ( $\mathrm{p}=$ 0.075 ). Whereas, in the width measurement, the mean reduction was $0.39 \pm 0.02$ with a statistically significant difference in the width before and after fractional $\mathrm{CO}_{2}$ LASER treatment $(\mathrm{p}=0.001)$. Naeini and colleagues in 2012 and 2014 stated that changes in both SA length and width showed varied results. In both studies, the clinical change evaluation was carried out based on measurements of digital photography by measuring the length and width using PictZar digital planimetry software before treatment and four weeks after the procedure. They found that there was a decrease in the mean length measurement of $0.62 \pm$ 0.53 and $0.41 \pm 0.43$ in width measurements with no significant difference between the two groups ( $p$-value $=0.03){ }^{10}$

The fractional $\mathrm{CO}_{2}$ LASER has varying waves and energies so that it can produce a desired wound healing time duration tailored for each individual. The
LASER has a shorter recovery period and minimal side effects. In this study, the ratio of fractional $\mathrm{CO}_{2}$ LASER treatment that caused side effects was $69 \%$ of 42 patients. The statistical analysis found a significant relationship in skin phototypes, parameters, and preoperative diagnosis. Meanwhile, there were no significant differences based on sex and onset or duration of illness (Table 5). A similar retrospective study conducted by Emmy and colleagues involving 422 patients who received fractional $\mathrm{CO}_{2}$ LASER treatment found that only observed side effects in $7.6 \%$ of the patients. The side effects found were only significantly related to the patient's skin phototype, and not significant by sex, LASER parameters, and preoperative diagnosis. ${ }^{18,21}$

The side effects found in this study were hyperpigmentation $(59.5 \%)$, crustae $(26.2 \%)$, erythema $\geq 4$ days $(19 \%)$, new acne $(19 \%)$, edema $\geq 2$ days $(9.5 \%)$, and hypopigmentation $(2.4 \%)$ (Table 6$)$. No patient reported any side effects of bacterial or viral infection, which is one of the most common local side effects in the areas receiving LASER treatment. The statistical test results, as presented in table 6 showed that there was a significant difference in the incidence of side effects of hyperpigmentation, crustae, erythema $\geq 4$ days, and new acne, but there was no difference for edema $\geq 2$ days and hypopigmentation as indicated by their p-values, which was 0.052 and 0.319 , respectively. A similar retrospective study, conducted by Harumi and colleagues in 2017 involving 107 patients with acne scars, found that $15 \%$ of patients experienced side effects after fractional $\mathrm{CO}_{2}$ LASER treatment, where the incidence of side effects increased with the number of procedures performed. It is said that fractional $\mathrm{CO}_{2}$ LASER treatment on scars can reduce the incidence of post-treatment side effects and provide a better safety profile compared to conventional ablative $\mathrm{CO}_{2}$ LASER. $^{8}$

In darker skin types, such as the population in Indonesia, post-inflammatory hyperpigmentation (PIH) is the most common side effect, including in this study where PIH was found in most subjects (59.5\%). Chan and colleagues' study on patients in China with skin types III-IV reported the incidence of PIH of $55.5 \%$ after one month of post-treatment. Manuskiatti and colleagues in Thailand even found $92.3 \%$ of $\mathrm{PIH}$ cases after fractional $\mathrm{CO}_{2}$ LASER treatment in patients with skin type IV. This result is relatively much higher than the studies reported in western countries where only $1.27 \%$ of PIH cases were found after fractional $\mathrm{CO}_{2}$ LASER treatment. The findings were in line with research conducted by Ryu and colleagues in 2013. They stated that patients with skin phototypes IV-V had a greater risk of developing PIH compared to skin 
phototypes I and II. In this study, we observed side effects in patients with darker skin types. Although, the statistical test result was not significantly different (4.31 vs 4.15) with p-value $=0.480$ (Table 5) ${ }^{8,22}$

We observe prolonged erythema in $19 \%$ subjects in this study. The criteria for prolonged erythema and edema were referred to research conducted by Emmy and colleagues. This was in line with research conducted by Lee and colleagues in 2014 which reported that erythema, after fractional $\mathrm{CO}_{2}$ LASER treatment, was expected, usually, only lasted less than three days. Prolonged erythema is defined if it persisted for more than 3 days. The occurrence of hyperpigmentation, crustae, and erythema that occur in the scars, for example in the acne scars, was related to the inflammatory process. In inflammation, erythema and vasodilation occur after the vasoconstriction phase due to the homeostasis process. Melanogenesis is also stimulated. Inflammation plays an important role in the discoloration of the scars because it causes injury to the pigmented epithelium that melanin is released into the dermis, and it produces brownish pigmentation. ${ }^{21} \mathrm{~A}$ limitation of this study is the relatively small patient group. Effect and side effect observed in this study were temporary and did not result in long term adverse sequele and this data based on medical records of patients there are any risk a numerous bias.

In conclusion, this study revealed that Carbon dioxide ablative fractional resurfacing LASER appeared to be effective, and well tolerated for the treatment of acne scars, keloid, and striae albae in IIIV Fitz Patrick skin type. Post-inflammatory hyperpigmentation was the most common adverse effect observed among the subjects. Future work up would be beneficial, including longer follow up periods for the assessment of possible late side effects changes. In additions, with sufficient sample size optimizing parameter selection for darker skin type patients needs further study to achieve better outcomes.

\section{REFERENCES}

1. Saedi N, Jalian HR, Petelin A, and Zachary C. Fractionation: Past, Present, Future. In: Seminars in Cutaneous Medicine and Surgery. Chicago: Elsevier 2012; p.138-60.

2. Patil UA, Dhami LD. Overview of LASERs. Indian J Plast Surg 2012; 41(3): S101-13.

3. Busse B. Introduction to wound healing. In: Busse B. Editor Wound management in urgent care. Philadelphia: Springer International Publishing 2016; p. 1-5.

4. Falanga V, Imamoto S. Mechanisms of wound repair, wound healing, and wound dressing. In: Goldsmith LA, Katz SI, Gilchrist BA, Paller AS,
Leffel DJ, Wolff K, editor-editor. Fitzpatrick's Dermatology in general medicine. 8th edition. New York: Mc Graw Hill Companies 2012; p. 2984-96.

5. Alves RO, Boin MFC, Crocco EI. Striae after topical orticosteroid: treatment with nonablative fractional LASER 1540nm. J Cosmet Ther 2015; 93(2):1-5.

6. Clementoni MT, Lavagno R. A novel $1565 \mathrm{~nm}$ non-ablative fractional device for stretch marks: a preliminary report. J Cosmet LASER Ther 2015; 89:1-8.

7. Chapas AM, Brightman L, Sukal S. Successful treatment of acneiform scarring with $\mathrm{CO} 2$ ablative fractional resurfacing. Lasers Surg Med 2011; 40(06):381-6.

8. Harumi O, Tan L, Tan WP, GOH CL. Treatment of facial acne scarring with fractional carbon dioxide laser in Asians, a retrospective analysis of efficacy and complications. Dermatol Surg 2017; $0: 1-7$.

9. Lee SM, Kim MS, Kim YJ, Won CH, Lee MW, Choi JH et al. Adverse Event of Non Ablative Fractional Photothermolysis: A Retrospective of Study 856 Treatment in 362 Patient. Int J1 of Dermatol 2014; 25(4):304-7.

10. Naeini FF, Nikyar Z, Mokhtari F, Bahrami A. Comparison of the fractional $\mathrm{CO} 2$ laser and the combined use of a pulsed dye laser with fractional $\mathrm{CO} 2$ laser in striae alba treatment. Adv Biomed Res 2014; 3: 184-6.

11. Kaur J, Sharma S, Kaur T, Bassi R. Complications of fractional ablative carbon dioxide laser in various aesthetic procedures: a retrospective study. Int J Res Dermatol 2019; 5(4): 664-7.

12. Lee SM, Kim MS, Kim YJ, Won CH, Lee MW, Choi JH et al. Adverse Event of Non Ablative Fractional Photothermolysis: A Retrospective of Study 856 Treatment in 362 Patient. Int J1 of Dermatol 2014; 25(4):304-7.

13. Huang L. A new modality for fractional $\mathrm{CO} 2$ laser resurfacing for acne scars in Asians. Lasers Med Sci 2013; 28(02): 627-32.

14. Magnani LR, Schweiger ES. Fractional CO2 lasers for the treatment of atrophic acne scars: a review of the literature. J Cosmet Laser Ther 2014; 16(02): 48-56.

15. Fabbrocini G, Annunziata MC, Arco VD, Vita VD, Lodi G, Mauriello MC et al. Review article: Acne scars: pathogenesis, classification and treatment. Dermatol research 2010; 129(9): 213641. 
16. Gonzales DFM, Navalta JTP. The efficacy and safety of fractional ablative resurfacing using $10,600 \mathrm{~nm}$ CO2 pulse wave in the treatment of striae distensae among filipino women with skin types III-V, a preliminary investigation and initial results. Am J Clin Dermatol 2012; 19(3): 405-23.

17. Crocco EI, Mantovani PA, Volpini BMF. In search of treatments for striae rubra and striae alba: a dermatologists' challenge. Surg Cosmet Dermatol 2012; 4(4): 332-7.

18. Al-Himdani S, Ud-Din S, Gilmore S, Bayat A. Striae distensae: A comprehensive review and evidencebased evaluation of prophylaxis and treatment. Br J Dermatol 2014; 170(3): 527-47.

19. Reinke MJ, Sorg H. Wound repair and regeneration. European Surg Reasearch 2012; 35 -
43.

20. Scrimali L, Lomeo G, Nolfo C, Pompii G, Tamburino S, Catalani A. Treatment of hyperthrophic scar and keloids with fractional CO2 laser: a personal experience. J Cosmet Laser Ther 2010; 12:218-21.

21. Emmy MG, Tanzi EL, Alster TS. Side effects and complications of fractional laser photothermolysis: Experience with 961 treatment. Dermatol surg 2011; 34: 301-7.

22. Ryu HW, Kim SA, Jung HR, Ryoo YW, Lee KS, Cho JW. Clinical improvement of striae distensae in korean patients using a combination of fractionated microneedle radiofrequency and fractional carbon dioxide LASER. Dermatol Surg 2013; 11(12): 12108-17. 